\begin{tabular}{|c|c|c|}
\hline institute & $\begin{array}{l}\text { CARADDE: Jurnal Pengabdian Kepada Masyarakat } \\
\text { https://journal.ilininstitute.com/index.php/caradde } \\
\text { Volume 1 | Nomor 2 | Februari | } 2019 \\
\text { e-ISSN: } 2621-7910 \text { dan p-ISSN: 2621-7961 } \\
\text { DOI: https://doi.org/10.31960/caradde.v1i2.76 }\end{array}$ & 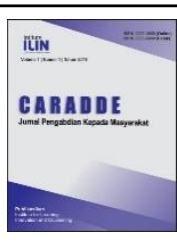 \\
\hline
\end{tabular}

\title{
Peningkatan Kompetensi Teknologi dan Informasi Guru Bimbingan dan Konseling
}

\author{
Wening Cahyawulan ${ }^{1}$, Aip Badrujaman ${ }^{2}$, Hilma Fitriyani ${ }^{3}$, Michiko Mamesah ${ }^{4}$,Eka \\ Wahyuni $^{5}$, Djunaedi ${ }^{6}$
}

\begin{tabular}{ll}
\hline \hline Keywords : & Abstrak. Kompetensi teknologi dan informasi bagi guru \\
Kompetensi Teknologi; & bimbingan dan konseling/konselor merupakan kompetensi \\
Guru Bimbingan dan Konseling; & $\begin{array}{l}\text { yang perlu dimiliki. Hal ini dikarenakan, kompetensi } \\
\text { teknologi dan informasi akan membantu guru bimbingan dan }\end{array}$ \\
Pelatihan. & konseling/konselor melaksanakan administrasi bimbingan \\
& dan konseling yang cenderung memakan waktu, seperti \\
Corespondensi Author & analisis hasil asesmen. Pengabdian pada masyarakat \\
Bimbingan dan Konseling, & dilakukan dengan metode pelatihan yang bertujuan untuk \\
Universitas Negeri Jakarta & meningkatkan kompetensi teknologi guru bimbingan dan \\
Jakarta & konseling/konselordiwilayah DKI Jakarta. Pengabdian pada \\
Email: wening@unj.ac.id & masyarakat melibatkan 28 orang guru bimbingan dan \\
& konseling di wilayah DKI Jakarta. Berdasarkan hasil \\
History Artikel & pelaksanaan pengabdian pada masyarakat, diperlukan \\
Received: November-2018; & adanya pendampingan bagi peserta ketika menerapkan \\
Reviewed: Desember-2018 & kompetensiteknologidan informasi dalam layananbimbingan \\
Accepted: Januari-2019 & dan konseling di sekolah masing-masing. \\
Published: Februari-2019 &
\end{tabular}

(1) This work is licensed under a Creative Commons Attribution

4.0 International License

\section{PENDAHULUAN}

Guru bimbingan dan konseling/konselor adalah seorang profesional yang melayani siswa di sekolah. Guru bimbingan dan konseling/konselor membantu siswa agar dapat mencapai tugas perkembangannya. Dalam menjalankan tanggungjawab tersebut, guru bimbingan dan konseling/konselor bekerja berdasarkan program yang telah disusun sesuai kebutuhan.

Berdasarkan Peraturan Menteri Pendidikan dan Kebudayaan Nomor 111 Tahun 2014 tentang Bimbingan dan Konseling, layanan dalam bimbingan dan konseling terdirid dari 4 (empat) layanan, yaitu layanan dasar, layanan responsif, layanan perencanaan individual, dan dukungan sistem. Dalam usaha memaksimalkan pelaksanaan keempat layanan bimbingan dan konseling, guru bimbingan dan konseling/konselor perlu memiliki kompetensi teknologi dan informasi. Myers dan Gubson (1999) menyatakan terdapat dua belas kompetensi teknologi untuk guru bimbingan dan konseling/konselor yang disebut dengan Technology Competence of Counselor Educators (ACES), yaitu (1) mampu menggunakan perangkat lunak yang produktif untuk mengembangan web pages, presentasi, surat, laporan, dan sebagainya; (2) mampu menggunakan peralatan audiovisual seperti perekam video, perekam audio, peralatan proyeksi, dan playback units; (3) mampu berlangganan, berpartisipasi, dan keluar dari listservs yang berhubungan dengan konseling; (4) mampu mengases dan menggunakan database CD-Rpm yang berhubungan dengan konseling; (5) mampu 
menggunakan email; (6) mampu menggunakan perangkat statistika berbasis komputer; (7) mampu menggunakan program tes, diagnosis, dan pengambilan keputusan karier berbasis komputer dengan klien; (8) mampu membantu klien mencari berbagai tipe informasi yang berkaitan dengan konseling tentang karier, kesempatan kerja, kesempatan pendidikan dan pelatihan, bantuan keuangan/beasiswa, prosedur treatment, serta informasi sosial dan pribadi; (9) memiliki pengetahuan tentang hukum dan kode etik yang berhubungan dengan layana konseling dengan internet; (10) memiliki pengetahuan tentang kekuatan dan kelemahan layanan konseling yang disediakan melalui internet; (11) mampu menggunakan internet untuk mencari dan menggunakan kesempatan pendidikan yang berkelanjutan dalam konseling; serta (12) mampu mengevaluasi kualitas informasi internet.

Faktanya pada saat ini, guru bimbingan dan konseling/konselor masih mengalami kendala untuk mengintegrasikan penggunaan teknologi dan informasi dalam pekerjaannya. Guru bimbingan dan konseling/konselor masih menggunakan angket berbasis kertas (paper-based) dalam kegiatan asesmen, tidak membuat laporan evaluasi program bimbingan dan konseling, dan sebagainya. Berbagai kendala tersebut dikarenakan guru bimbingan dan konseling/konselor masih memiliki kompetensi teknologi dan informasi yang rendah.

Di Indonesia, program bimbingan dan konseling yang diterapkan adalah program bimbingan dan konseling komprehensif yang dikemukan oleh Gysbers dan Henderson (2012). Dalam penyusunan program bimbingan dan konseling komprehensif terdapat empat langkah pengembangan, yaitu perencanaan (planning), desain (designing), implementasi (implementing), dan evaluasi (evaluating) (Gysbers \& Henderson, 2012). Khususnya pada tahap perencanaan, guru bimbingan dan konseling/konselor akan melakukan asesmen untuk mengetahui kebutuhan peserta didik. Asesmen yang dilakukan menggunakan adalah asesmen teknik non tes, yaitu alat ukur terstandar diantaranya Daftar Cek Masalah (Komalasari, Wahyuni, \& Karsih, 2011). Daftar cek masalah dikembangkan oleh Ross L. Mooney, dengan nama the Mooney Problem Checklist. The Mooney Problem Checklst sangat bermanfaat dalam mengumpulkan informasi awal (Nezu, Nezu, \& D'Zurilla, 2013). Selain menggunakan alat ukur yang telah terstandar, guru bimbingan dan konseling juga dapat menggunakan angket. Angket sebagai salah satu alat pengumpul data dalam asesmen tes merupakan serangkaian pertanyaan atau pernyataan yang diajukan pada responden, seperti siswa, orangtua, atau masyarakat.

Pelaksanaan asesmen merupakan hal yang mendasar dalam program bimbingan dan konseling. Hal ini dikarenakan melalui asesmen, guru bimbingan dan konseling/konselor dapat menentukan kebutuhan dan permasalahan yang dialami peserta didik. Melalui data yang didapatkan saat asesmen, maka guru bimbingan dan konseling dapat mengembangan program bimbingan dan konseling komprehensif yang sesuai untuk siswa.

Pentingnya pelaksanaan asesmen juga dijelaskan dalam regulasi negara, yaitu Peraturan Menteri Pendidikan dan Kebudayaan Nomor 111 Tahun 2014 tentang Bimbingan dan Konseling. Melalui peraturan tersebut dijelaskan bahwa guru bimbingan dan konseling/konselor perlu mendeskripsikan kebutuhan siswa berdasarkan hasil asesmen kebutuhan siswa.

Saat ini proses pengumpulan data yang dilakukan oleh guru bimbingan dan konseling/konselor dilakukan dengan berbasis kertas (paper-based). Saat ini, kegiatan pengumpulan data memanfaatkan penggunaan kertas yang banyak. Selanjutnya ketika melakukan analisis, guru bimbingan dan konseling/konselor akan memasukkan data satu per satu sejumlah siswa di sekolah.

Proses pengumpulan data yang dilakukan oleh guru bimbingan dan konseling/konselor saat ini mengakibatkan data yang hanya terkumpul namun tidak dianalisis. Data yang tidak dianalisis mengakibatkan program bimbingan dan konseling komprehensif yang menjadi kerangka kerja guru bimbingan dan konseling/konselor tidak sesuai dengan kebutuhan siswa.

Permasalahan tersebut dapat diatasi jika guru bimbingan dan konseling memanfaatkan aplikasi google form yang merupakan salah satu fitur dari Google. Google 
form memungkinkan pengguna membuat form elektronik untuk mengumpulkan berbagai tipe data (Santillo, 2018). Selain itu, guru bimbingan dan konseling juga dapat memanfaatkan analisis asesmen secara daring yang telah dikembangkan dalam website 2.0. Berube (2011) menjelaskan bahwa Web 2.0 adalah sebuah istilah hidup yang mendeskripsikan tren dalam penggunaan teknologi World Wide Web dan web design yang bertujuan untuk meningkatkan kreativitas, berbagi informasi kolaborasi, dan fungsi dari web. Konsep web 2.0 membuat perkembangan dan evlousi dari komunitas web-based dan layanan domain, seperti halaman jejaring sosial, berbagi video, wiki, blog, dan folsonomi.

Berdasarkan analisis situasi, guru bimbingan dan konseling/konselor masih memiliki kompetensi teknologi dan informasi yang rendah. Hal ini mengakibatkan, guru bimbingan dan konseling/konselor tidak dapat melakukan administrasi bimbingan dan konseling yang baik. Oleh sebab itu, perlu ada peningkatan kompetensi teknologi dan informasi bagi guru bimbingan dan konseling/konselor.

\section{METODE}

Metode pendekatan yang digunakan dalam pengabdian kepada masyarakat adalah pelatihan. Pelatihan adalah upaya sadar untuk menumbuhkembangkan perubahan (Sudjana, 2007). Pelatihan ini berorientasi untuk memenuhi kebutuhan guru bimbingan dan konseling/konselor sebagai sasaran.

Pelatihan melibatkan 28 orang guru bimbingan dan konseling di wilayah DKI
Jakarta. Pelatihan dilaksanakan selama tiga hari, yaitu (1) hari pertama mengenai kompetensi dasar komputer dengan materi Microsoft Word dan Microsoft Excel, (2) hari kedua mengenai pemanfaatan google form dalam penyusunan angket, serta (3) hari ketiga mengenai pemanfaatan Daftar Cek Masalah secara daring melalui website.

\section{HASIL DAN PEMBAHASAN}

Berdasarkan indikator yang telah ditetapkan, maka keberhasilan kegiatan dilihat dari dua aspek, yaitu aspek proses dan aspek hasil. Aspek proses pada kegiatan terdiri dari kehadiran peserta, ketepatan waktu, dan kehadiran narasumber. Sedangkan aspek hasil pada kegiatan ini adalah pemahaman peserta terhadap materi pelatihan.

Aspek proses pada kegiatan pengabdian masyarakat ini adalah kehadiran peserta, ketepatan waktu, dan kehadiran narasumber. Kegiatan dihadiri oleh 28 orang peserta yang merupakan guru bimbingan dan konseling di DKI Jakarta. Peserta sesuai dengan target karena jumlah komputer di labratorium komputer program studi (S-1) Bimbingan dan Konseling yang berfungsi dengan baik adalah sejumlah 28 komputer. Kegiatan dilaksanakan sesuai dengan perencanaan, yaitu dimulai pada pukul 08.00 WIB, selanjutnya kegiatan selesai pada pukul 16.00 WIB.

Kegiatan yang dilaksanakan selama tiga hari melibatkan tim narasumber yang ahli pada bidangnya, diantaranya dosen bimbingan dan konseling serta pengembang website daftar cek masalah online.

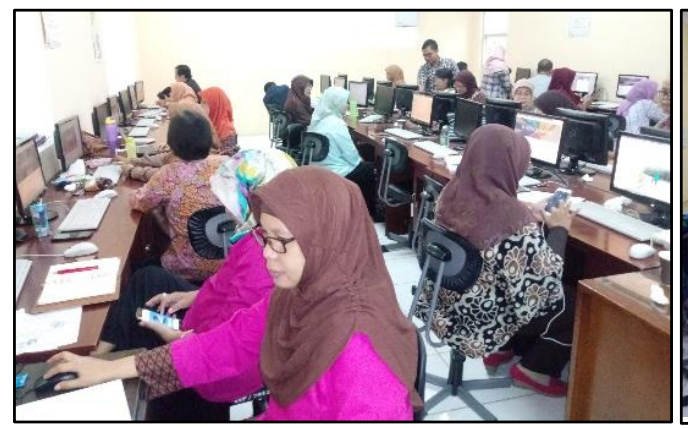

Gambar 1: Tim Memberikan Pelatihan

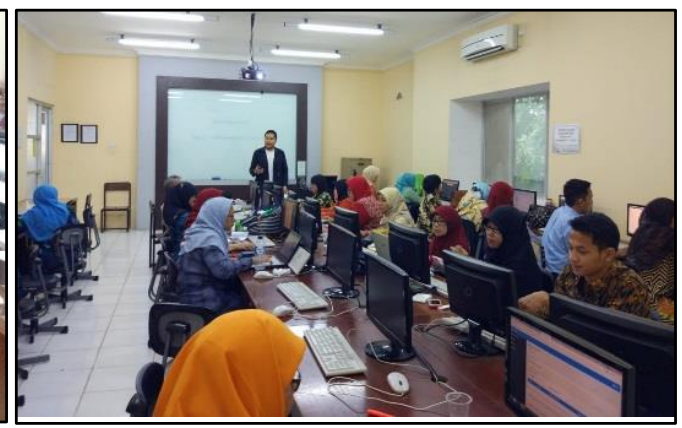

Evaluasi hasil dilaksanakan dengan menggunakan angket yang disebarkan

menggunakan google form kepada peserta pelatihan. Hasil analisis evaluasi hasil terdapat 
pada tabel 1 .

\begin{tabular}{lcccc}
\hline \multicolumn{1}{c}{ Pernyataan } & $\begin{array}{c}\text { Sangat } \\
\text { Rendah }\end{array}$ & Rendah & Tinggi & $\begin{array}{c}\text { Sangat } \\
\text { Tinggi }\end{array}$ \\
\hline Keterampilan menyimpan dokumen & 9,1 & 9,1 & 72,7 & 9,1 \\
Keterampilan memanfaatkan fitur clipboard & 9,1 & 0 & 81,8 & 9,1 \\
Keterampilan memanfaatkan fitur font & 9,1 & 18,2 & 63,6 & 9,1 \\
Keterampilan memanfaatkan fitur paragraph & 9,1 & 36,4 & 45,5 & 9,1 \\
Keterampilan memanfaatkan fitur illustration & 9,1 & 45,5 & 36,4 & 9,1 \\
Keterampilan menyusun penomoran & 18,2 & 36,4 & 36,4 & 9,1 \\
Keterampilan mengelola spreadsheet & 9,1 & 36,4 & 45,5 & 9,1 \\
Keterampilan mengelola kolom dan baris dalam & 9,1 & 27,3 & 54,5 & 9,1 \\
spreadsheet & & & & \\
Keterampilan memanfaatkan fitur clipboard dalam Ms. & 9,1 & 9,1 & 72,7 & 9,1 \\
Excel & & & & \\
Keterampilan menyusun rumus dalam spreadsheet & 9,1 & 54,5 & 27,3 & 9,1 \\
Keterampilan membuat angket dengan google form & 9,1 & 63,6 & 18,2 & 9,1 \\
Ketrampilan membuat google sites & 18,2 & 72,7 & 9,1 & 0 \\
$\begin{array}{l}\text { Keterampilan memasukkan angket google form di } \\
\text { dalam google sites agar dapat diakses oleh siswa }\end{array}$ & 27,3 & 63,6 & 9,1 & 0 \\
Keterampilan membuat akun melalui website Daftar & 9,1 & 63,6 & 27,3 & 0 \\
Cek Masalah & & & & \\
$\begin{array}{l}\text { Keterampilan mengolah hasil Daftar Cek Masalah } \\
\text { melalui website }\end{array}$ & 9,1 & 72,7 & 18,2 & 0 \\
\hline
\end{tabular}

\section{Tabel 1. Evaluasi Hasil Pelatihan}

Berdasarkan hasil analisis pada evaluasi hasil, tampak bahwa sebagian besar peserta berada pada kategori tinggi pada kompetensi dasar teknologi dan informasi. Hal tersebut menunjukkan sebagian besar peserta dapat mengolah dokumen dan data menggunakan Microsoft Word dan Microsoft Excel. Pentingnya penguasaan Microsoft oleh guru juga disadari di Uganda sehingga pelatihan terhadap guru juga dilaksanakan di Uganda (Unwin, 2005).

Pada pemanfaatan google form dalam mengembangkan angket, sebagian besar peserta masih berada pada kategori rendah. Hal tersebut menunjukkan bahwa pelatihan perlu dilanjutkan dengan kegiatan pendampingan pada peserta. Pendampingan perlu dilakukan khususnya ketika peserta mulai menerapkan kompetensinya dalam menjalankan kegiatan asesmen di sekolah. Keterampilan memanfaatkan google form merupakan keterampilan yang penting karena google form sebagai salah satu tools social networking dapat meningkatkan interaksi di kelas (Habibi et al., 2018).

Pada topik yang ketiga, yaitu pemanfaatan website pengolahan Daftar Cek Masalah, sebagian besar peserta membutuhkan pendampingan lebih lanjut dalam pemanfaatan website. Hal ini ditunjukkan dari banyaknya peserta yang masih berada pada kategori rendah. Padahal penggunaan website sebagai internet-based assessement dalam pengolahan Daftar Cek Masalah memungkinkan instrumen dapat diakses 24/7, mudah digunakan, skor dapat langsung dihasilkan, dan mengurangi administrasi tes (Drummond \& Jones, 2009).

\section{SIMPULAN DAN SARAN}

Berdasarkan pembahasan hasil kegiatan, maka terdapat beberapa kesimpulan yang dapat diambil, meliputi (1) egiatan bermanfaat untuk guru bimbingan dan 
Cahyawulan, Badrujaman, Fitriyani, Mamesah, Wahyuni, Djunaedi. Peningkatan Kompetensi Teknologi

konseling yang selama ini merasa banyak waktunya tersita karena urusan administrasi, serta (2) kegiatan bermanfaat untuk guru bimbingan dan konseling yang selama ini tidak memiliki waktu menganalisis dan menginterpretasi hasil asesmen karena penggunaan angket dengan kertas.

Saran untuk pelaksanaan pengabdian masyarakat selanjutnya adalah perlu dilaksanakan kegiatan pendampingan kepada peserta yang merupakan guru bimbingan dan konseling dalam menerapkan kompetensi yang didapatkan dalam kegiatan bimbingan dan konseling. Kegiatan pendampingan yang dibutuhkan diantaranya pendampingan dalam mengimplementasikan peggunaan Microsoft Office dalam kegiatan administasi bimbingan dan konseling, pendampingan dalam mengimplementasikan penggunaan Google Form untuk kegiatan asesmen di sekolah, serta pendampingan dalam mengimplementasikan penggunaan website pengolah data Daftar Cek Masalah dalam pelaksanaan kegiatan asesmen.

\section{Daftar Rujukan}

Berube, L. (2011). Do You Web 2.0?: Public Libraries and Social Networking. Oxford: Chandos.

Drummond, R. J., \& Jones, K. D. (2009). Assessment Procedures for Counselors and Helping Professionals (7th ed.). London: Pearson.

Gysbers, N. C., \& Henderson, P. (2012). Developing and managing your school guidance and counseling program (5th ed.). Alexandria: American Counseling
Association.

Habibi, A., Mukminin, A., Riyanto, Y., Prasojo, L. D., Sulistiyo, U., Sofwan, M., \& Saudagar, F. (2018). Building an online community: Student teachers' perceptions on the advantages of using social networking services in a teacher education program. Turkish Online Journal of Distance Education, 19(1), 46-61. https://doi.org/10.17718/tojde.382663

Komalasari, G., Wahyuni, E., \& Karsih. (2011). Asesmen Teknik Nontes dalam Perspektif BK Komprehensif. Jakarta: Indeks.

Myers, J. E., \& Gibson, D. M. (1999). Technology Competence of Counselor Educators. ERIC Digest.

Nezu, A. M., Nezu, C. M., \& D'Zurilla, T. J. (2013). Problem-Solving Therapy. Handbook of Cognitive-Behavioral Therapies. New york: Springer.

Santillo, K. L. (2018). Google Forms in the Classroom. Butler, Pennsylvania: Author.

Sudjana, D. (2007). Pendidikan dan Pelatihan. In Ilmu dan Aplikasi pendidikan. Bandung: Imperial Bhakti Utama.

Unwin, T. (2005). Towards a framework for the use of ICT in teacher training in Africa. Open Learning, 20(2), 113-129. https://doi.org/10.1080/026805105000 94124 